\title{
Obituary
}

\section{William Robert Henderson}

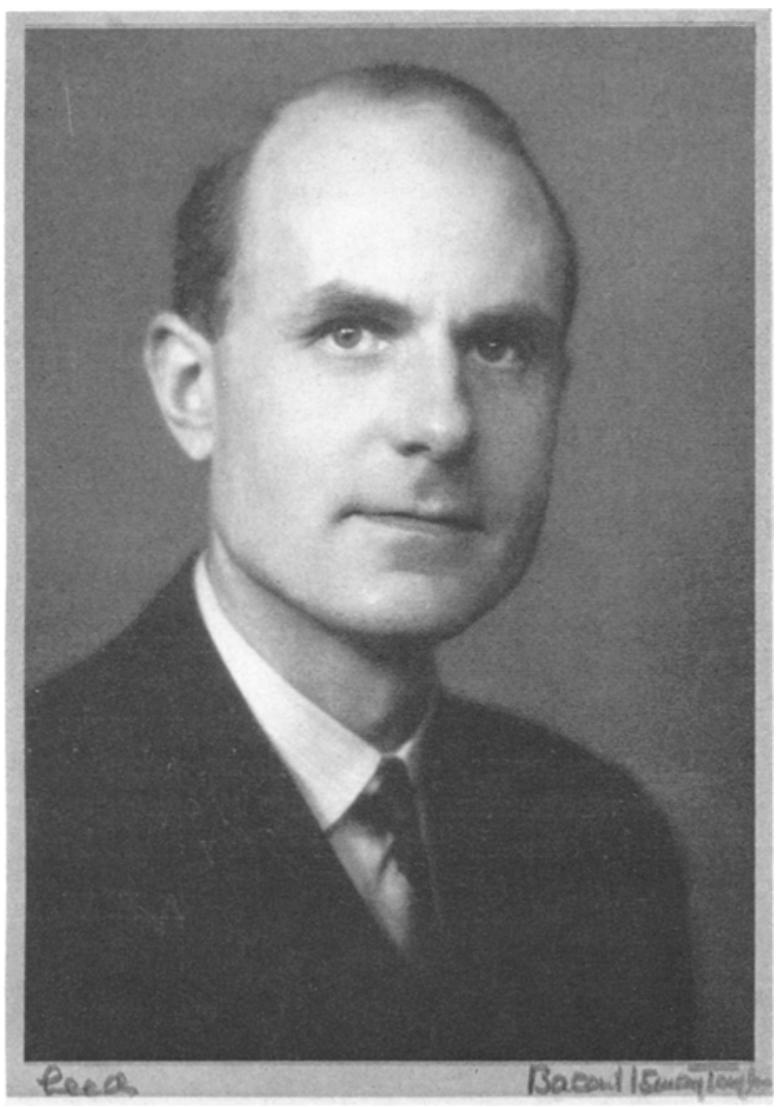

Mr. W. R. Henderson, Honorary Consultant Neurosurgeon to the General Infirmary at Leeds, died on November 30th, 1975.

In 1938 he was appointed as Leeds' first specialist Neurosurgeon but was there for only about one year when he was selected as Neurosurgeon in charge of the No. 1 Army Mobile Neurosurgical Unit based at Oxford. The Unit worked, largely in General Surgery, 
during the retreat to Dunkirk and was captured intact. Willie's special qualities of determination, calm, surgical skill, and patience were of particular value in such a situation, and he became famous as one of the surgical team at the P.O.W. Hospital in Obermassfeld. During this period he gained a vast experience of peripheral nerve injuries and the subtle effects of amputation and, as would be expected, much of the carefully collected data later appeared in print. Later he was transferred to Colditz and ended the war in a more passive role. In 1946, after a few months attached to the Military Hospital for head injuries in Oxford, he returned to Leeds and gradually expanded the Neurosurgical service in the region. He retired in 1969 leaving an active and flourishing Unit.

During his many years in Leeds he practised Neurosurgery with imposing skill and endless patience, whether at the bedside or in the theatre, and his numerous pupils will forever be grateful for his guidance and example. His standards were always high, and he was intolerant of anything slipshod either in clinical examination or in operating. He was a hard taskmaster, but the patients and the novice surgeon were the benefactors.

He was greatly respected both locally and nationally and was for many years Secretary and later President of the Society of British Neurological Surgeons.

His shyness and reserve made him appear somewhat aloof and unapproachable but, once the breach was made, everybody found him a man of immense integrity and honesty, a man with a great sense of humour and a great dislike of humbug.

$\mathrm{He}$ will be best remembered for his written works on pituitary tumours, basal meningiomas, phantom limbs, trigeminal neuralgia, and angiomas. He will be remembered also by colleagues as a delightful personality and a staunch supporter of any cause he thought just.

A. E. WALL (Leeds) 